\title{
The sense of proportion: two thoughts about the governance of direct-to-consumer genetic testing for children
}

\section{Peter Mills ${ }^{1}$}

There is an established consensus in clinical ethics around the position that genetic testing of children is morally justified only when there are important medical benefits to be obtained from the testing that cannot otherwise be obtained and that should not be delayed. (I'll call this 'the presumption to defer'.) This position is expressed by a growing number of official and professional bodies ${ }^{2}$ and is now increasingly codified, for example, in the genetic testing protocol of the Council of Europe Convention on Human Rights and Biomedicine. ${ }^{3}$ This is a position with which the Nuffield Council on Bioethics, in its report Medical Profiling and Online Medicine, ${ }^{4}$ substantially agrees. Below are some brief parerga concerning the grounds on which positions concerning the control of genetic testing may be established and the way in which they may be given effect.

The first thought I want to express is that a rights-based discourse of individual autonomy of the sort that infuses clinical ethics is, in two important ways, maladapted to thinking about many of the genetic tests on offer in a commercial setting. These maladaptations are in relation to, firstly, the privacy impact of the tests and, secondly, the familial context within which they are commissioned.

The presumption to defer may be grounded in the claim that subjecting children to genetic testing takes away their freedom in some important way, and that this must be justified by weighty reasons. This is not just - not principally - a problem of coercion but of foreclosing a future choice of anticipated value: it relies on a prolepsis. ${ }^{5}$ (Although the claim to this freedom is sometimes formulated as a 'right not to know' information that may become an unwelcome burden to them in later life, it is more coherently understood as the right to make an autonomous choice between knowing and not-knowing, as an aspect of privacy.)

While the presumption to defer looks strong in relation to pre-symptomatic or highly predictive genetic testing for adult onset conditions, such conditions are rare and, probably or possibly (depending on one's view about the prospects of genomic medicine), will come to account for a decreasing proportion of genetic testing overall. While the degree of infringement of a person's autonomy is, by hypothesis, equivalent in all cases in which a decision about testing is made by another person (i.e. the choice whether to know the results is removed to the same extent in each case) the results of this choice are likely to have markedly different implications depending on the nature of the test. Generalising the defaults of clinical genetics risks framing all testing decisions in a way that sees burdening an individual with predictive information about Huntington's disease as having equal significance to burdening them with information about a mutation that some studies claim might explain their fondness for fatty foods. 
Outside questions of clinical decision-making framed by limit cases (for example: HD: knowing can't help; PKU: knowing helps a lot), knowing genetic information may have a variety of different meanings within the family and social context. ${ }^{6}$ When one considers the dendritic nature of successive options taken and forsaken by families it is by no means obvious that greater autonomy will secured by preserving that one particular degree of freedom represented by the choice to take a genetic test (although no one will bear the responsibility for actively removing it). Information circulating within families, be it a boon or a burden, constitutes the life world; it is not merely contingent to it. It is surely not possible, 10 or 15 years later, to call up again the choices that were available in childhood, and simply to step onto an alternative road not taken. If the predictive or associative value of genetic information is not sufficiently high that a reasonable person would ground important decisions in it then the appropriate response might be to explain this clearly and convincingly: one might promote clinical rationality as a principle for the consumption of genetic testing as a social aim, not as a moral injunction.

The second thought I want to express is that, to be effective, the discourse of ethics has to engage with the disposition of facts; it has to legislate in the real world. Failure to do so makes it not only irrelevant but possibly also counterproductive.

The Medical Profiling and Online Medicine report takes the fact of direct-toconsumer genetic testing seriously. It acknowledges that tests exist and are available, whether or not they would meet the exacting standards of clinical utility. All that is needed to secure a genetic profile, besides the will and the financial wherewithal, is internet access and a postage stamp. Providers may be assumed to be highly sensitive to regulation: restrict their activity here and they will pop up elsewhere. They cannot be contained, they cannot be silenced and, to all intents and purposes, their activities cannot be detected. The transfer of genetic testing from the local clinic to the global marketplace requires the adoption of a different strategy.

Acknowledging these developments, the Nuffield Council adopts a pragmatic approach: it looks at the harms that direct-to-consumer genetic testing (among other biomedical innovations) might represent and recommends proportionate, practical measures in the light of the current evidence of harms. Rather than asking: what conditions should be met for such practices to be permissible, the question the Council asks is: given that such practices exist, what is the best way to respond to them? This leads to recommendations that, for example, help consumers think about what they should be able to expect from genetic testing companies, and encourage companies to develop and adopt good practice, operate transparently and responsibly. $^{7}$

That is not to say that we should not be concerned about the very pertinent difficulty particularly when carried out through the media of the internet and postal services - of establishing whether the commissioning agent actually has parental responsibility. While it is undoubtedly true that 'by clicking this box I confirm that I have read and agree to the conditions of use' is, for the most part, a mendacious connivance when

Genomics, Society and Policy, Vol.6, No.3 (2010/11) ISSN: 1746-5354

(C) ESRC Genomics Network. 
viewed as informed consent, when viewed as a record, whether in the form of piece of paper or a byte of digital information, it is evidence of a deliberate act. In the UK, for example, it might be evidence in a prosecution under section 45 of the Human Tissue Act $2004 .{ }^{8}$ That might make some people think again - although it may not make them think deeply. ${ }^{9}$

There is a tendency, linked to the legal tradition deriving from the Napoleonic Code, one that inspires measures such as the Council of Europe Convention referred to above, to regard 'soft law' approaches - recommendations, codes of practice, statements of principle - as imperfect approximations or steps along the route to hard law, rather than equally good, possibly preferable alternatives to it. The reality is that direct-to-consumer genetic testing is not a well defined, regulated and jurisdictionally circumscribed sector but nor is it demonstrably harmful, in general, to the bodily integrity or the privacy of individuals. All this means that to approach it by an enlargement or transfer of established medical supervisory procedures may not only be missing the point but facing in entirely the wrong direction.

\footnotetext{
${ }^{1}$ Nuffield Council on Bioethics. bioethics@nuffieldbioethics.org

${ }^{2}$ For example, the Human Genetics Commission, The European Society for Human Genetics, The British Society of Human Genetics, The Joint Committee on Genetic Testing.

${ }^{3}$ Art 10 of the Additional Protocol on Genetic Testing for Health Purposes to the Council of Europe Convention for the Protection of Human Rights and Dignity of the Human Being with regard to the Application of Biology and Medicine: Convention on Human Rights and Biomedicine (Oviedo Convention).

${ }^{4}$ Nuffield Council on Bioethics (2010) Medical profiling and online medicine: the ethics of 'personalised healthcare' in a consumer age.
}

${ }_{5}$ A fortiori, it does not restrict present freedom, since the presumption to defer assumes that that freedom cannot be exercised in the present and the decision therefore falls to another agent. Of course, some flexibility with regard to the test of capacity in relation to impact responds more sensitively to the reality of testing situations.

${ }^{6}$ Without wishing to belabour this point it may be observed that the transpersonal nature of genetic information (and proxy information) raises significant issues that medical ethics does not always deal with well, that are not easily tractable within the distinct categories of ownership (mine/yours) and consent (agent/patient) through which rights-imbued injunctions of clinical ethics have developed. One should also be wary - because forecasting is difficult - about making the assumption that the social meaning of genetic mutation in humans, hitherto framed by the clinical implications of single-gene disorders, will remain the same over time as, ex hypothesi, the variety of its implications is increasingly understood. Furthermore, the meaning of genetic information, for example, information from a genetic profile, may change as interpretations change in the light of changing knowledge about gene-gene or gene-environment interactions.

${ }^{7}$ The report acknowledges that evidence of greater harms should prompt more stringent action, although it is difficult to see where this might lead. But such action should at least be led by the evidence rather than by speculative fears.

${ }^{8}$ Although Scotland has a separate act - The Human Tissue (Scotland) Act 2006, section 45 of the England and Wales Act is applicable throughout the UK.

${ }^{9}$ One should not, of course, confuse consent with the record of consent, nor the possession of responsibility with the claim to have that responsibility. The problem to which box ticking gives rise is not one of representation but of authentication: not how the intention should be interpreted but how the agent's identity should be verified. 